\title{
MANEJO DIAGNÓSTICO Y TERAPÉUTICO DE LA HIDATIDOSIS RENAL
}

Pablo Luis Guzman Martinez-Valls, Beatriz Honrubia Vilchez, Almudena Rodríguez Tardido, Emilio Izquierdo Morejon, Bogdan-Nicolau Pietricica, Raúl Montoya Chinchilla, Antonio Rosino Sanchez, Gregorio Hita Villaplana, Antonio Romero Hoyvela y Bernardino Miñana Lopez.

Servicio de Urología. Hospital General Universitario Morales Meseguer. Murcia. España.

\section{CORRESPONDENCIA}

Pablo L. Guzmán Martínez-Valls

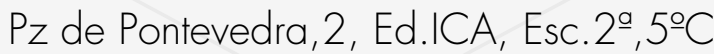
30009 Murcia. (España).

pabloguzman@terra.es

Trabajo recibido: 17 de febrero 2008. 
Resumen.- OBJETIVO: La hidatidosis renal está causado por Echinococcus granulosus y es extremadamente infrecuente, constituyendo el 3-4\% de los casos de hidatidosis, siendo la tercera localización tras el hígado y pulmones. Habitualmente permanece asintomático durante años y los síntomas más comunes son dolor, sensación de pesadez en flanco y disuria. Ante la aparición de un cuadro compatible, estudiamos la pauta diagnóstica, terapéutica y de seguimiento revisando la literatura.

MÉTODOS: Realizamos una búsqueda bibliográfica electrónica PubMed (MEDLINE) con términos MESH "Equinococcosis"[MeSH] AND "Urinary Tract"[MeSH] y de citas bibliográficas. Hacemos una revisión de la epidemiología, el ciclo vital del parásito y del manejo del paciente afecto de Hidatidosis. La gran mayoría de las publicaciones corresponden a aportación de casos con diferentes localizaciones, aunque encontramos algunas revisiones.

RESULTADOS: Encontramos un total de 137 trabajos de los cuales, seleccionamos veintitres por estar relacionados; cinco correspondían a revisiones, referenciamos en el texto sólo diez. Aunque la mayoría son aportación de casos, las revisiones analizan el ciclo del Echinococcus y los diferentes lugares de asentamiento (órganos) en el huésped hombre. El hombre puede llegar a ser huésped intermedio a través de contacto con huésped definitivo (perros...) o por ingesta de agua contaminada o vegetales.

CONCLUSIONES: Gracias a la combinación de anamnesis, estudios de imagen y serología nos aproximamos al diagnóstico hasta en un 80\%. En muchos casos es posible la cirugía conservadora pero tras la sospecha debemos siempre esterilizar con Albendazol antes del tratamiento quirúrgico y tras el tratamiento monitorizar mediante serología la titulación de Anticuerpos anti-echinococcus.

Palabras clave: Hidatidosis. Quiste hidatídico renal. Albendazol.

Summary.- OBJECTIVE: Renal hydatidosis is caused by Echinococcus granulosus and is extremely rare, accounting for $3-4 \%$ of the cases of hydatidosis, being the third site after liver and lungs. It generally remains asymptomatic for years and the most frequent symptoms are pain, feeling of flank heaviness, and dysuria. In front of a compatible clinical picture, we studied the diagnostic, therapeutic, and follow-up schemes reviewing the literature.

METHODS: We performed an electronic bibliographic search in PubMed (MEDLINE) which MESH terms " Echinococcosis"[MeSH] AND "urinary tract" $[\mathrm{MeSH}]$ and bibliographic citations. We perform a review on epidemiology, vital cycle of the parasite and management of patients with hydatidosis. Most published papers correspond to case reports from different localisations, although we found some reviews.

RESULTS: We found a total of 137 papers, we selected 23 of them because they were related; five were reviews, but we only include 10 of them in our references. Although most were case reports, the reviews analyse the cycle of the Echinococcus and its various host sites (organs) in the human host. The human being may become an intermediary host through contact with the definitive host (dogs) or by taking contaminated water or vegetables.

CONCLUSIONS: Thanks to the combination of history, imaging tests and serology we get close to the diagnosis in up to $80 \%$. In many cases conservative surgery is possible, but after suspicion we should always sterilise with albendazole before surgical treatment, and monitor serum titles of antiEchinococcus antibodies.

Keywords: Hydatidosis. Renal hydatid cyst.
Albendazole.

\section{INTRODUCCIÓN}

La hidatidosis en una antropozoonosis producida por la larva del Echinococcus. Endémica en África, Sudamérica, Medio y lejano Este, Australia y área mediterránea. Las dos principales especies causantes son la $E$. granulosus y la $E$. multilocularis. El hombre sirve como huésped accidental para ambas especies. La incidencia aproximada en nuestro medio es 18 casos/100.000 habitantes (1). La localización mas frecuente es la hepática en un $50-60 \%$, pulmonar en un $25 \%$. La afectación renal es poco común, incluso en las poblaciones mas afectadas, se calcula que representa entre el $1-4 \%$ de los quistes hidatídicos (2-6). Suelen ser asintomáticos durantes muchos años. Los quistes son frecuentemente solitarios y localizados en la corteza y pueden llegar a medir más de $10 \mathrm{~cm}$ y mostrar sintomatología (7). Los quistes en más de un $18 \%$ pueden romperse al sistema colector y producir un cólico renal e hidatiduria (8). Existen otras localizaciones en el árbol urológico: vejiga (9), vesículas seminales o en retroperitoneo (10).

\section{CASO CLínICO}

Paciente de 58 años de origen subsahariano que acude a Urgencias por sudoración y fiebre con dolor lumbar izquierdo, pesadez en flanco de dicho lado y disuria de unos 15 días.

Dentro de sus antecedentes personales no destaca ninguna patología trascendente: No DM. No HTA. No aler- 
gias conocidas. Ex fumador de 8 años. No hematuria. No cólicos. No ITUs.

Relata que en las últimas dos semanas presenta febrícula ocasional, sudoración, pesadez en flanco izquierdo con dolor lumbar del mismo lado y clínica miccional con chorro aceptable, disuria, no entrecortado, no goteo, no urgencia con frecuencia miccional nocturna de una vez y diurna cada 3-4 horas con sensación de vacuidad completa.

A la exploración física se aprecia a nivel abdominal, efecto masa en flanco izquierdo a la palpación profunda, Tacto Rectal: próstata grado I-II sin lesiones sospechosas.

Las pruebas complementarias presentaban: Hemograma normal con signos de Eosinofilia. Bioquímica normal. Resto normal, analítica de orina negativa. Rx aparato genito urinario (Figura 1) presentaba efecto masa en flanco izquierdo que borraba la línea del psoas de dicho lado. Ecografía renal: múltiples quistes en riñón izquierdo (Figura 2). Se realiza TC abdominopélvico (Figura 3): con lesiones quísticas con vesículas hijas, compatible con enfermedad hidatídica renal.

Se solicita serología de Anticuerpos Echinococcus/Hemag que es POSITIVO a cifras superiores 1/2.621.440.

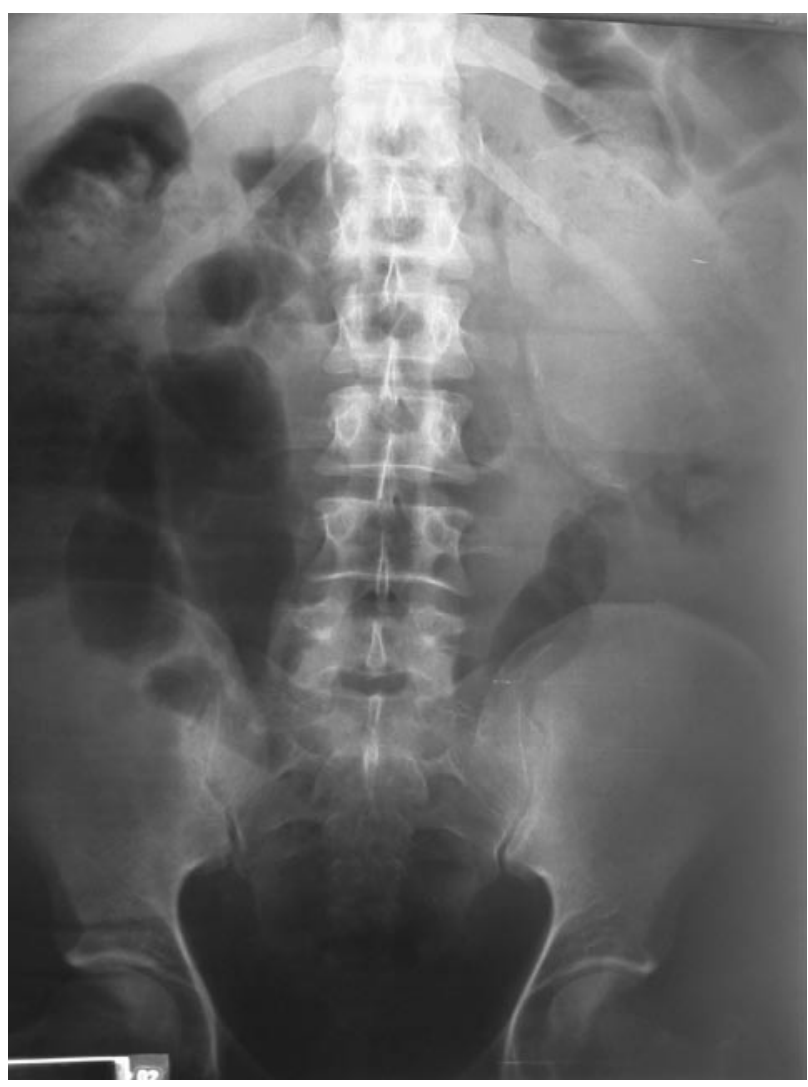

Se completa estudio con RMN (Figura 4) para tener una iconografía mas completa y valorar relaciones con estructuras adyacentes.

Ante la sospecha diagnóstica, se decide cirugía sobre la unidad renal afecta, siendo imposible durante el acto quirúrgico realizar cirugía conservadora practicándole al paciente una nefroureterectomía izquierda completa por sospecha de comunicación del quíste hidatídico con la vía ante el grosor de la misma. Previo al tratamiento quirúrgico el paciente recibe un ciclo de Albendazol y otro tras la cirugía.

El paciente tras el tratamiento presenta caída de las cifras de titulación de anticuerpos y a tres años del procedimiento el paciente está asintomático y analíticamente sin enfermedad.

\section{DISCUSIÓN}

La distribución geográfica de la hidatidosis es amplia, pero es endémica en la región Mediterránea, África, Sudamérica, Medio Este, Australia y Nueva Zelanda. (Figura 5). En nuestro medio debe tenerse en consideración en el diagnóstico diferencial de las masas renales, pese a su escasa incidencia (5).

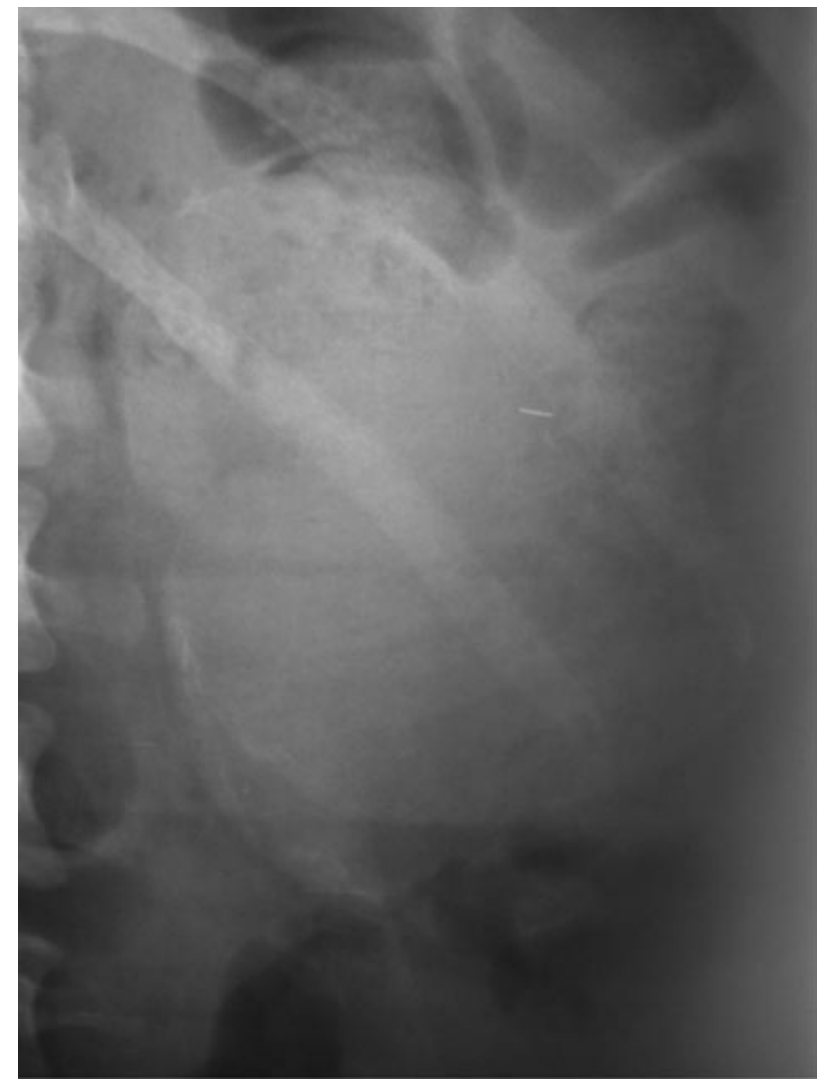

FIGURA 1. Rx aparato genitourinario simple: efecto masa en flanco izquierdo, con borramiento de línea de psoas. 


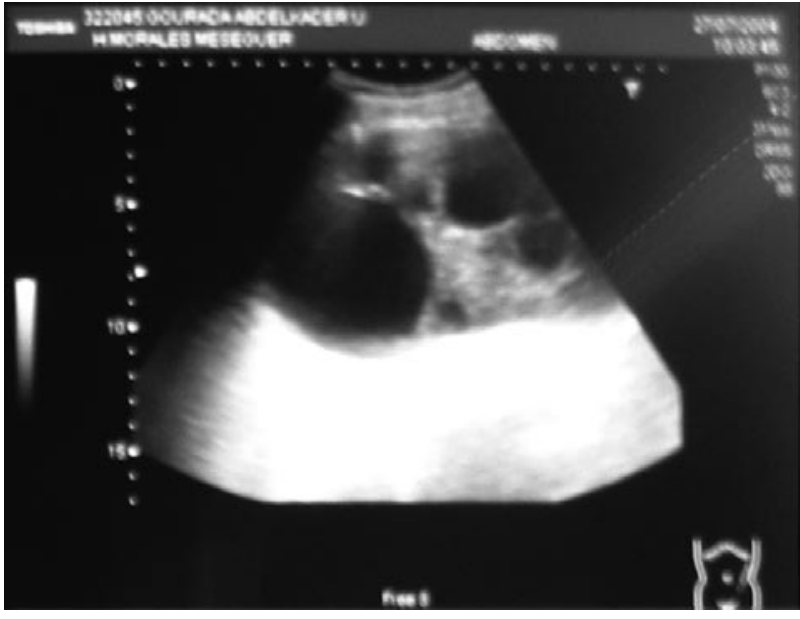

FIGURA 2. Ecografía con detalle de los múltiples quistes.

La hidatidosis es una zoonosis producida por la larva del Echicoccocus secundaria a la transmisión a través del ciclo vital del parásito, ciclo perro-oveja que sirven como huésped definitivo (aunque puede haber otros carnívoros) e intermedio respectivamente. El hombre puede llegar a ser huésped intermedio a través del contacto con el huésped definitivo (perro doméstico) o por la ingesta de agua o vegetales contaminados. (Fig.6). El gusano adulto del parásito vive en el intestino delgado del huésped definitivo, enganchado a la mucosa. Los huevos se producen en el interior del intestino del huésped y se excretan por las heces. La oveja, que es el huésped intermedio más frecuente, ingiere el óvulo mientras pasta en suelos contaminados. El óvulo pierde su capa protectora y es digerido en el duodeno. Se liberan las oncosferas por efecto del $\mathrm{HCL}$ en el estómago y pasan a la circulación portal y de ella al hígado (primer filtro); si sobrepasan éste, alcanzan las venas suprahepáticas y cava inferior llegando a los pulmones (segundo filtro); por esa razón es excepcional la localización de la enfermedad hidatídica extrahepática o extrapulmonar, como es la renal. Cuando el huésped definitivo come la víscera del huésped intermedio, el ciclo está completado (4-7).

La afectación renal ocurre en un $3-4 \%$ de los casos $(3,4,7)$. Suele ser asintomático durante muchos años,

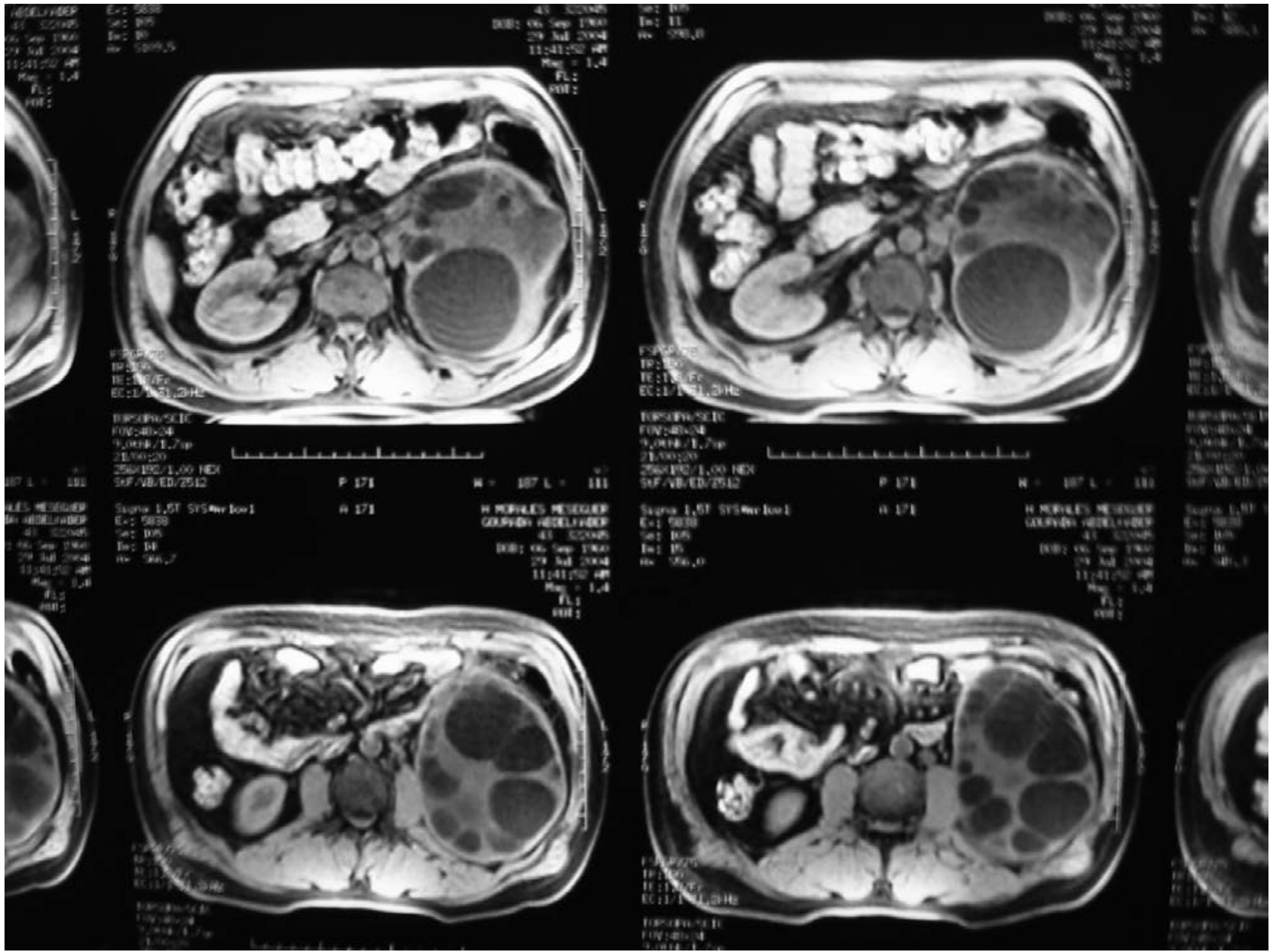

FIGURA 3. TC: imagen de quiste hidatídico con su vesículas hijas. 
siendo los síntomas más comunes el dolor, sensación de pesadez en flanco y la disuria. Los quistes habitualmente son únicos y localizados en la corteza renal; éstos suelen producir la sintomatología cuando alcanzan tamaños de $10 \mathrm{~cm}$. El hallazgo de una masa renal calcificada plantea el diagnóstico diferencial de quiste renal complicado, neoplasia renal y quiste hidatídico. En menos de la mitad de los pacientes presentan eosinofilia en la analítica $(2,6)$ y es raro que afecte a la función renal, ya que mayoritariamente la afectación es focal.
La serología es una herramienta útil en el diagnóstico. La sensibilidad varía en función de la localización de la enfermedad hidatídica, así los quistes pulmonares, bazo y riñón se asocian a bajos niveles de de anticuerpos. A pesar de no existir un test sensible y específico al $100 \%$ porque existen falsos positivos, el test positivo junto a clínica y pruebas radiológicas apoyan el diagnóstico (1-11)

La ecografía muestra que la lesión es multiquística con ecogenicidad variable, La urografía permite valorar
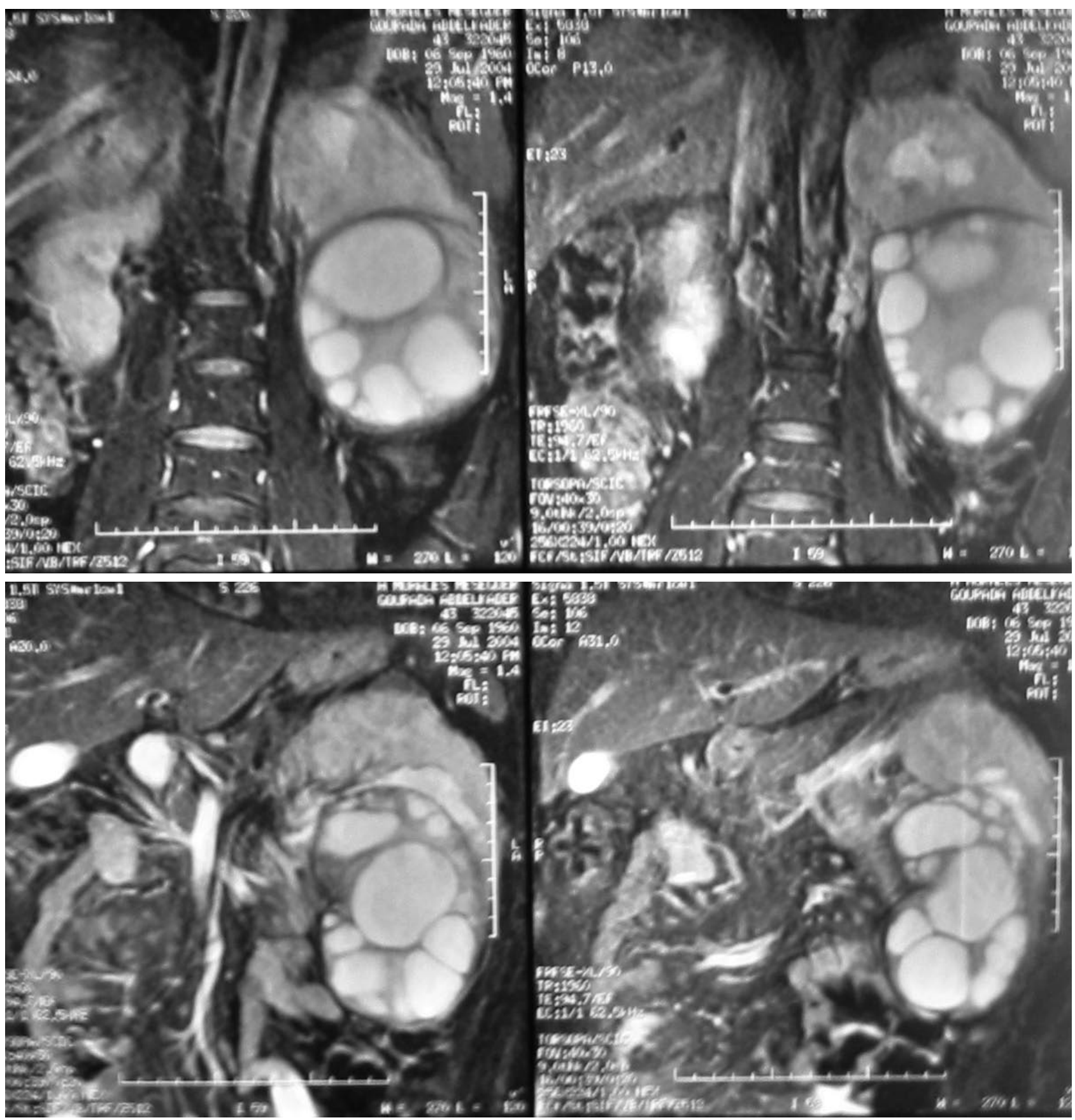

FIGURA 4. RMN: detalle de quiste hidatídico. Vesículas hijas. 


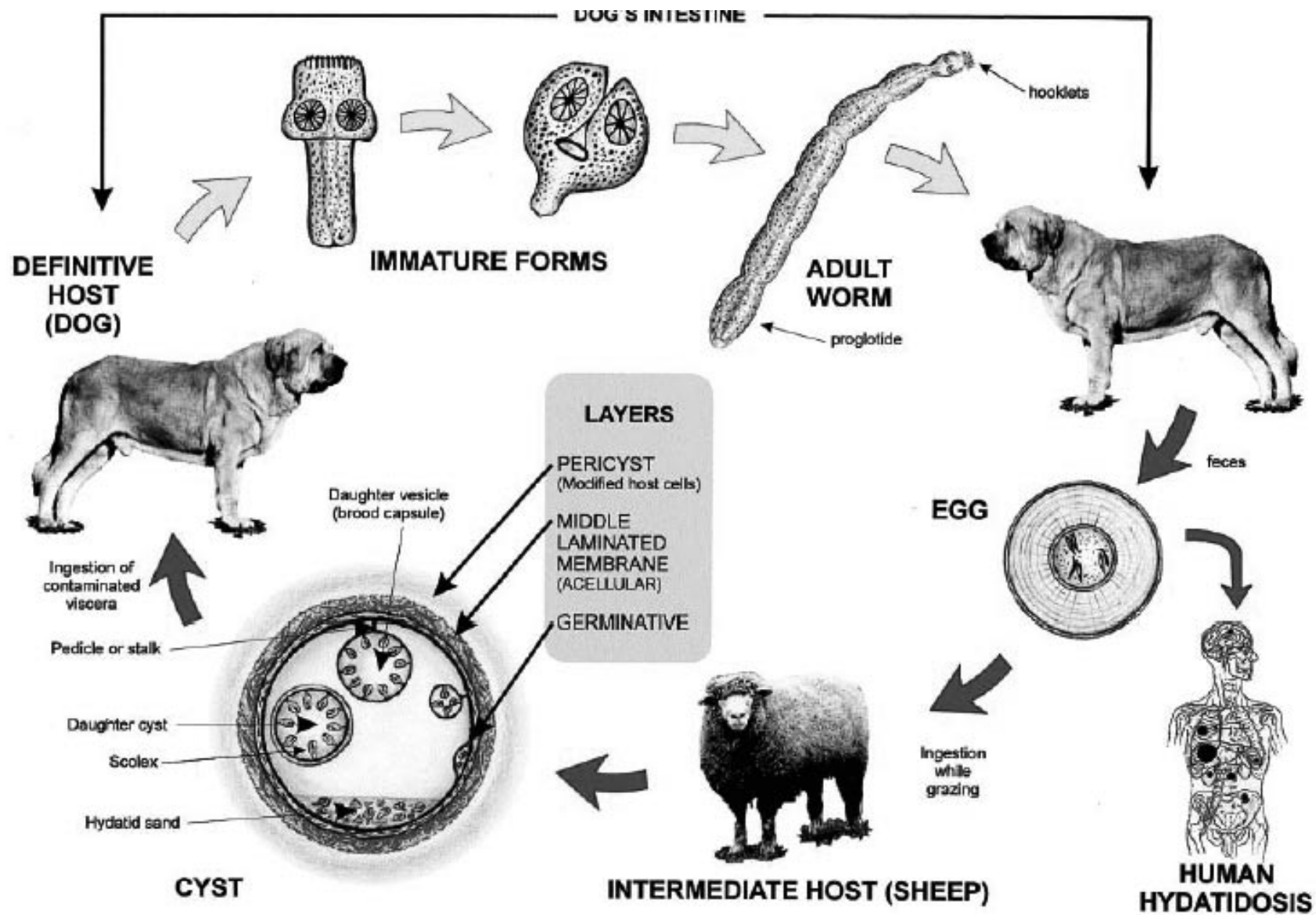

FIGURA 5. Ciclo vital (ciclo perro-oveja). Tomado de Pedrosa et al (7).

efecto masa, calcificación e incluso la ocupación de la vía pero no es de primera línea. Es el TC y la RMN las que permite el diagnóstico en un alto porcentaje. En la imagen obtenida del TC y de la RMN la apariencia del Echinococcus en el riñón es tan característica como en otros órganos. La presencia de quistes o vesículas hijas diferencian estas lesiones de otro tipo como los quistes renales, abscesos renales, quistes infectados o tumores necrosados (7).

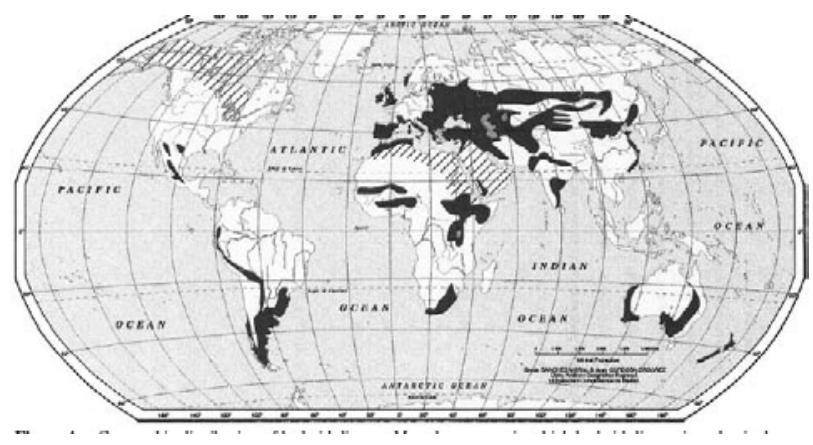

FIGURA 6. Distribución geográfica de la hidatidosis. Tomado de Pedrosa et al (7).
El tratamiento es quirúrgico, pero se debe administrar previamente siempre Albendazol para esterilizar ante la eventualidad de la rotura de los quistes, y así su diseminación o reacción anafiláctica grave si hubiera una abertura accidental durante el procedimiento. Siempre se recomienda tras el tratamiento propuesto, que puede ser conservador, si la localización lo permite, completar con un ciclo más de Albendazol.

Sabremos que el paciente ha sido curado y evoluciona satisfactoriamente con la monitorización de la titulación de anticuerpos y su desaparición, siempre que éstos hubieran estado elevados al diagnóstico.

\section{CONCLUSIONES}

La combinación de historia clínica, estudios de imagen, serología y estudios analiticos nos aproximan al diagnóstico hasta en un $80 \%$, ya que la hidatidosis renal simula otras enfermedades y es necesario la realización de un diagnóstico diferencial (4). En muchos casos es posible la cirugía conservadora pero tras la sospecha debemos siempre esterilizar con Albendazol antes del tratamiento quirúrgico y tras el tratamiento monitorizar mediante serología la titulación de anticuerpos anti-echinococcus. 


\section{BIBLIOGRAFIA y LECTURAS RECOMENDADAS ( ${ }^{*}$ lectura de interés $y^{* *}$ lectura fundamental)}

*1. Cayla J, Barquet N, Muñoz et al. Estudio epidemiológico de la hidatidosis en Cataluña (1977-1981). Med Clin 1986; 86:397-04.

**2. Gögüs C, Safak M, Baltaci S et al. Isolated renal hydatidosis: experience with 20 cases. J Urol 2003; 169:18689.

**3. Türker I, Tefekli A, Kilicaslan I et al. Hydatid Disease of the Kidney caused by Echinococcus multilocularis: A rare clinical entily. Urol Int 2001; 67:310-12.

**4. Angulo JC, Sanchez-Chapado M, Diego A et al. Renal echinococcosis: clinical study of 34 cases. J Urol 1997; 157: 787-94.

*5. Pastor J, Carrascosa V, Serramp A et al. Enfermedad Hidatídica de localización única. Actas Urol Esp 1999; $23: 729-31$.

*6. Abascal J M, Esquena S, Martos R et al. Quiste hidatídico renal simulando hipernefrona. Actas Urolo Esp 2005; 29:223-25.

**7. Pedrosa I, Saiz A, Arrazola J et al. Hydatid Disease: Radiologic and Pathologic Features and Complications. Radiographics 2000; 20:795-17.

*8. Ozaras R, Mert A, Yekeler E et al. Rupture of a Renal Hydatid Cyst into the Renal Pelvis. Internal Medicine 2004; 43:270-71.

*9. Hafsa C, Golli M, Kriaa S et al. Retrovesical hydatid cyst in children: report of 3 cases. J Radiol 2007; 88:968-71.

*10. Angulo JC, Escribano J, Diego A et al. Isolated retrovesical and extrarrenal retroperitoneal hydatidosis: clinical study of 10 cases and literature review. J Urol 1998; 159: 76-82.

*11. Muro Bidaurre I, Sanz Jaka JP, Recarte Barriola JA e Hernaez Manrique I. Quiste hidatídico retroperitoneal primario. Arch. Esp. de Urol 2000; 53, 3:268-71. 